
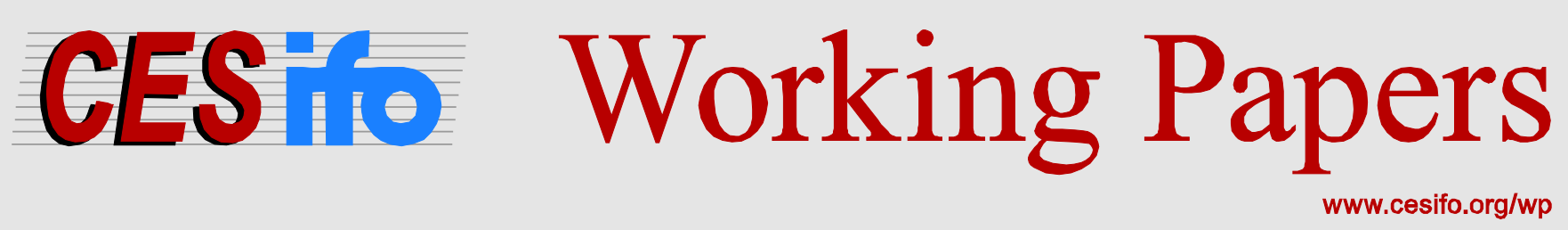

\title{
Inequality, Structure of Production and International Trade - The Role of Credit Market Imperfection
}

\author{
Hamid Beladi \\ Sugata Marjit \\ Suryaprakash Misra
}

CESIFO WORKING PAPER NO. 6307

CATEGORY 8: TRADE POLICY

JANUARY 2017

An electronic version of the paper may be downloaded

- from the SSRN website:

- from the RePEc website:

- from the CESifo website:

WwW.SSRN.com

www.RePEc.org

www.CESifo-group.org/wp 


\title{
Inequality, Structure of Production and International Trade - The Role of Credit Market Imperfection
}

\begin{abstract}
Credit rationing in the presence of asset inequality affects production and trade pattern in this paper, but not in the conventional way. A Ricardian general equilibrium framework with heterogeneous levels of asset ownership is developed to show that more equal asset distribution may contract the output of the credit intensive sector as redistribution to the bottom of the ladder fails to promote entrepreneurs. However, the same in favor of the middle of the ladder may do the opposite. We point out the possibility that an economy with relatively equal distribution of asset ownership may import capital or credit intensive good and also export capital, unlike in a conventional HOS model.
\end{abstract}

JEL-Codes: F120.

Keywords: credit, inequality, egalitarian distribution, trade.

\author{
Hamid Beladi \\ University of Texas at San Antonio \\ San Antonio / Texas / USA \\ hamid.beladi@utsa.edu
}

\author{
Sugata Marjit* \\ Centre for Studies in Social Sciences, \\ Calcutta, $R 1$ B. P. Township \\ India - Kolkata- 700094 \\ marjit@gmail.com
}

Suryaprakash Misra

National Law University

Delhi / India

*corresponding author

This version January 2017

Different versions of this paper have benefitted from lectures to students, seminars and discussions with the colleagues at the Australian National University, Monash University, CSSSC, University of Queensland, Federal Reserve Bank of St. Louis, Washington University in St. Louis, University of Konstanz and University of Pireaus. We acknowledge funding from the RBI endowment at CSSSC. Able research assistance of Arup Ratan Poddar has been quite helpful. The usual disclaimer applies. 


\section{Introduction}

Inequality of asset holding coupled with imperfect credit market usually leads to underinvestment and inefficiency when relatively poor cannot access sufficient credit from the banks and hence cannot invest to become entrepreneurs or towards skill formation. Credit rationing must affect the overall structure of production and pattern of trade. The purpose of this paper is to highlight this factor in terms of a Ricardian general equilibrium model. The recent literature on financial crisis has entirely focused on the issue of trade credit or trade finance. Interested readers may look at the very insightful papers of Manova (2013) and Schmidt-Eisenholr (2013). This paper is more related to the overall impact of credit market imperfection on international trade, inequality and capital flows not just in terms of the trade credit and is in the tradition of earlier contributions of Kletzer and Bardhan (1987), Matsuyama (2005), Deardorff (2000) Peters and Schnitzer (2015), etc. But it is structurally very different as it tries to relate degree of inequality to trade and capital flows. In spirit it is closest to Antras and Caballero (2009) as the present work develops a full-fledged general equilibrium model, but in a Ricardian continuum model with heterogeneity of asset ownership.

Redistributions of wealth from the rich to the poor may alleviate this problem. The purpose of this paper is to show that this does not work in a model where credit rationed firms are price takers and as a result redistribution of wealth actually reduces the size of the sector that badly needs credit. A more equal country will import credit intensive good and given an opportunity capital or credit may fly away from this economy to a more skewed destination. The nature of product market turns out to be critical.

Credit market imperfection coupled with uneven asset distribution can lead to inefficient outcomes. This issue has been dealt with the several sub disciplines of economics. The idea that with borrowing rate greater than lending rate one does not get first best outcome is well recognized. In development economics such anomalies lead to inadequate human capital formation and poverty traps as demonstrated in Banerjee and Newman (1993), Galor and Zeira(1993) and others. The literature on how inequality interacts with the development process and the underlying role of credit market imperfection has been elegantly summarized in Galor (2009). That the cost of external finance declines with the asset holding of the borrower has been well known in financial economics as discussed in Glenn Hubbard (1991). Credit market imperfection can be characterized by credit rationing, though all of the borrowers with varying amount of assets may not face a binding credit limit. Credit market 
imperfection has led to research on business cycles and endogenous growth such as Bernanke and Gertler (1989), Bencivenga and Smith (1991), Aghion and Banerjee (2005), etc. etc.

Sato (1996), Wynne (2005) and Foellmi and Oecschlin (2010) have looked at the impact of credit market imperfection and wealth inequality on entrepreneurship and trade. They discuss how inequality adversely affects production and trade and exports in the presence of credit constraints increase the degree of inequality. Smaller firms typically have less credit to work with and cannot expand production when trade expands as they engage in labor intensive sector. Results such as these and related ones in development economics in general are important because they signify positive contribution of public policies in mitigating the inefficiencies associated with uneven asset distribution. Remarkably popular book of Thomas Pickety (2013) has brought to the fore the issue of increasing inequality and growing income of the richest.

The purpose of this paper is to suggest that while human and social welfare driven arguments against inequality should have universal acceptance, the efficiency augmenting effects of redistributive justice have to be very carefully studied in the context of credit market imperfection and international trade. We prove in a Ricardian general equilibrium model of production and trade with standard characterization of credit market imperfection that more equal initial distribution of asset actually may hurt production and hence exports of credit intensive good. Such egalitarian schemes may not work in a model of perfect product market with large number of credit rationed firms. Hence, the obstacle to efficiency is not "inequality” as much but inequality coupled with product market imperfection. When product market imperfection is absent, effort to remove inequality may encourage inefficiency through an interplay of extensive and intensive margins.

Jones and Marjit (2001) have highlighted the potentially beneficial role of trade in capital poor economies in terms of entrepreneurial skill formation without explicit modeling of credit market imperfection. Bandyopadhyay, Marjit and Yang (2014) have shown the credit market considerations can affect trade policy outcomes, but they do not deal with the source of imperfections or pattern of trade.

The equity - efficiency correlation critically depends either on the diminishing productivity story whereby transferring to those who have less makes the system more productive or because the rich 
entrepreneurs do not face a binding credit limit whereas the poor ones do. Thus, if banks could transfer that surplus to the poor, production would have increased. However, such assertions will fail when firms, however rich they are, face binding credit constraint. This will happen in a competitive CRS world. Then any redistribution from richer segment may not be matched and compensated by those in the lower segment for the efficiency argument to hold. Any redistribution of assets among existing entrepreneurs in our model has no net effect on production. But any such strategy when applied between an existing entrepreneur and a poor worker may reduce production of credit intensive good. A more egalitarian economy tends to import credit intensive good and may drive away capital to another with a more skewed distribution of income. Papers that are relevant in this context are the well-known works of Lucas (1990) and Antras and Caballero (2009). Our results show that trade in goods and capital or credit can be substitute or complements depending on the nature of the asset distribution within the country. Capital may flow out of a poor country and a country with a more equal distribution may import capital intensive good and export capital at the same time. Thus it contains the flavor of the results discussed in above papers, though the framework and the mechanism are entirely different.

The paper is divided into five sections. The second one describes the basic model. The third describes the basic results i.e. the effect of inequality of asset distribution and trade. The next one deals with endogenous interest rate. The last section concludes.

\section{Model}

We have two sectors producing $X$ and $Y$ respectively. $X$ needs credit as well as labor while $Y$ needs only labor. Production of both $(X$ and $Y$ ) requires one unit of labor per unit of output. One can be a worker or an entrepreneur in $X$. As worker she gets the same wage as in $Y$. As an entrepreneur she hires workers, employs capital or credit which she may borrow from the bank and compares her opportunity cost of not being in $Y$.

Workers / Potential entrepreneurs are distributed in a continuum with assets $k(z), k^{\prime}>0, \in[0,1]$. Y is the numeraire good.

Opportunity cost of not being in $\mathrm{Y}$ is given by, $c(z)=r+k(z) \cdot r \ldots(1)$ 
(1) states that workers can invest their wage income and the asset to obtain rate of return $r . r$ is determined globally and is exogenous to the model. We treat $R=1+r$.

Profit of the $z^{\text {th }}$ entrepreneur in $X$ is given by,

$\pi(z)=P[B(z)+k(z)]-B(z) R-k(z) r \ldots(2)$

$B(z)$ denotes borrowing; $R$ (the borrowing rate) $>r$ (the deposit rate);

Competitive product markets imply that the individual firm takes $P$ as given.

Be an entrepreneur in $X$ iff,

$(P-R) B(z)+(P-r) k(z) \geq r \ldots(3)$

Note that $P>R>r$, otherwise $B(z)=0$

Also, individual demand for $B(z)$ at a given $P$ is unbounded. Since firms are competitive, they would like to sell as much as they can.

Banks are competitive in the sense that they face a constant deposit rate $r$ and charge a premium on $r$ to cover the intermediation costs. Competitive banking with intermediation cost implies $R=\mu r ; \mu=$ intermediation cost $>1$. But as $R>r$, external finance is more costly than own resources.

Banks worry about default [Aghion and Benerjee (2005)]. No default incentive constraint would be as follows.

$P[B(z)+k(z)]-B(z) R-k(z) r \geq P[B(z)+k(z)]-k(z) r-q \theta[k(z)+B(z)] \ldots$

Or, $B(z) \leq \frac{q \theta}{R-q \theta} k(z) \ldots(5)$

Where $q$ is the probability that the defaulter can be punished and if punished $\theta$ fraction of the total assets can be approximated by the bank.

We now derive the supply side of the model.

From (3), $k(\tilde{z})=\frac{r}{(P-R) \frac{q \theta}{R-q \theta}+(P-r)} \ldots$ 


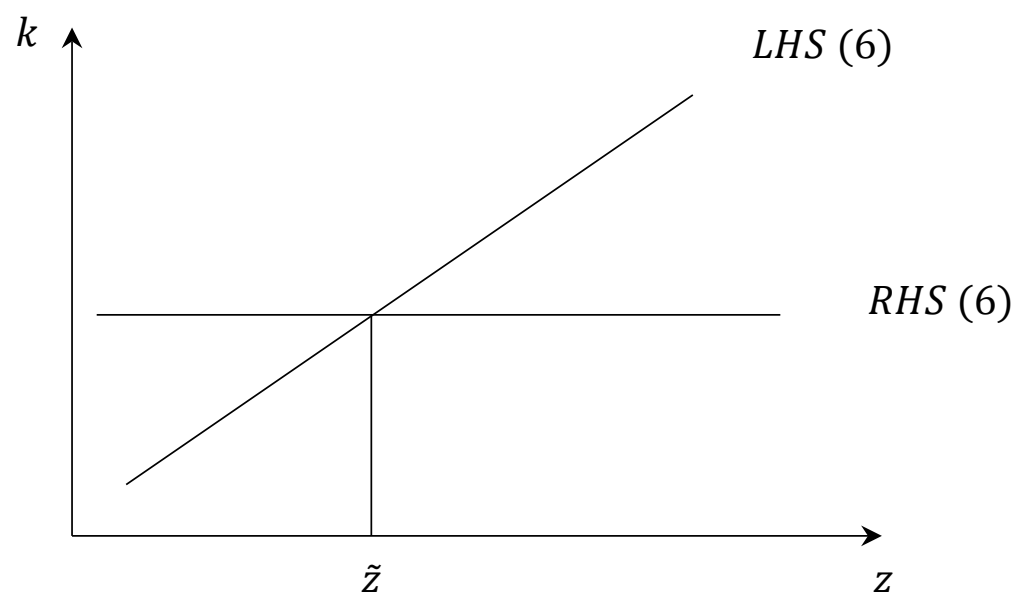

Figure (1)

If there is an interior equilibrium then $\forall z \geq \tilde{z}$, workers become entrepreneurs and $\forall z<\tilde{z}$, they choose to remain as workers. Note that our result here is consistent with the empirical finding of Rajan and Zingales (1998). If the banks can better audit and impose greater penalty on defaulters, each will get raise in terms of maximum amount of loan. This will expand the set of entrepreneurs leading to higher output of the credit-intensive good.

Total Output is determined as follows,

$X(\tilde{z})=\int_{\tilde{Z}}^{1} X(z) d z=\left(1+\frac{q \theta}{R-q \theta}\right) \int_{\tilde{Z}(P)}^{1} k(z) d z \ldots(7)$

$\frac{\delta X}{\delta P}>0$ as $\tilde{z}^{\prime}<0 \ldots$ (8)

$X(\tilde{z})+Y=\tilde{z}$, or, $\frac{X(\tilde{z})}{Y}=\frac{X(\tilde{z})}{\tilde{z}-X(\tilde{z})} \ldots$

as labor needs to be fully employed.

(9) defines the relative supply of $X$ as a function of $P$. As $P$ increases there are more entrepreneurs and less workers, expanding $X$ and contracting $Y$. We now close the model with a simple assumption of homothetic demand. Homothetic demand implies $\frac{X^{D}}{Y^{D}}=f(P) ; f^{\prime}<0 \ldots$ (10) 


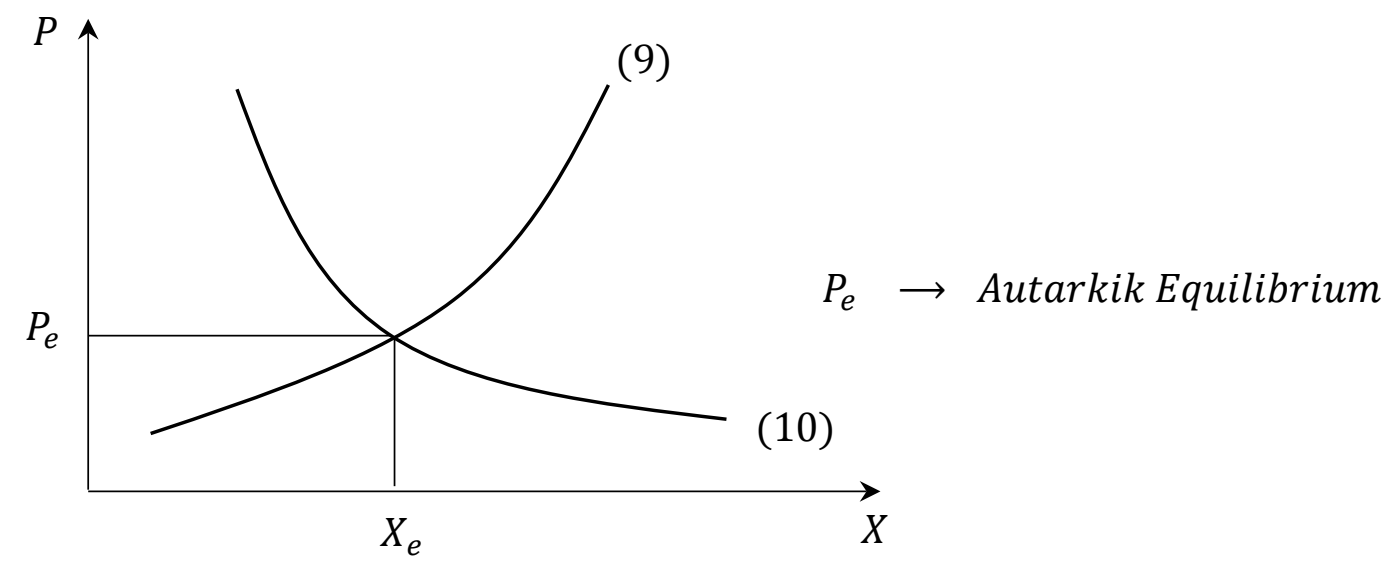

Figure (2)

Setting $(9)=(10)$, we determine the equilibrium relative price of $X, P_{e}$, in autarky.

Therefore, $k\left(\tilde{z}_{e}\right)=\frac{r}{\left(P_{e}-R\right) \frac{q \theta}{R-q \theta}+\left(P_{e}-r\right)} \ldots$ (11)

In equilibrium we have $\tilde{z}_{e}$ workers and $\left(1-\tilde{z}_{e}\right)$ entrepreneurs. $P_{e}$ denotes the autarkic equilibrium.

III. Given this setup, we now evaluate whether uneven initial distribution of asset is the root cause of lower production in the credit intensive sector, a generally accepted conclusion in the literature. In Figure 3(a), distribution 1 is less egalitarian and $z_{e}$ is the same for both the distributions at a given $P$. Then, for distribution 2, $X$ will be lesser for any given $P$. This will shift the relative supply curve to the left, increasing $P_{e}$.

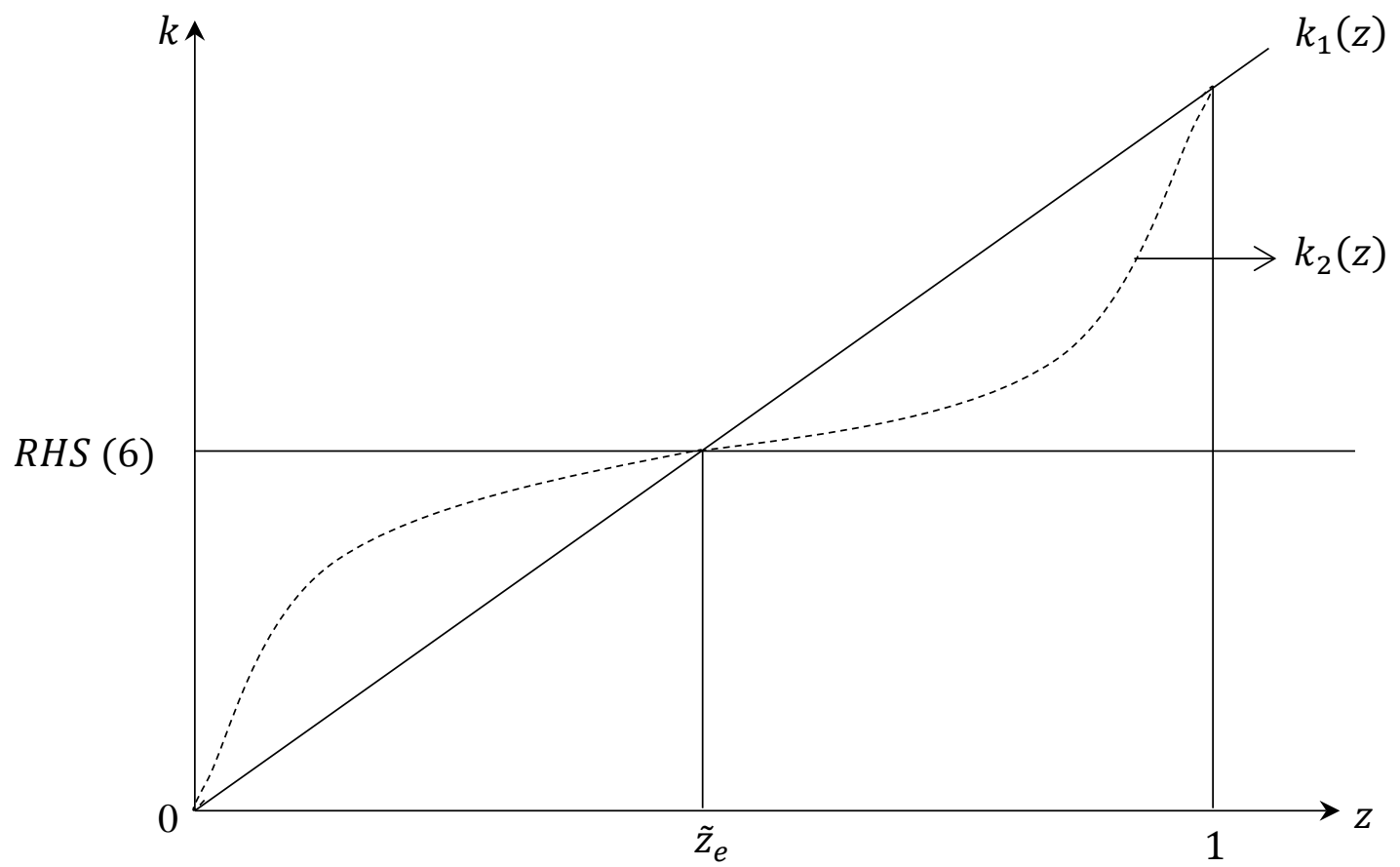

Fig 3(a) 


$$
\begin{gathered}
\int_{0}^{1} k_{1}(z) d z=\int_{0}^{1} k_{2}(z) d z=\bar{k} \\
\int_{0}^{\tilde{z}_{e}} k_{1}(z) d z<\int_{0}^{\tilde{z}_{e}} k_{2}(z) d z ; \quad \int_{\tilde{z}_{e}}^{1} k_{1}(z) d z>\int_{\tilde{z}_{e}}^{1} k_{2}(z) d z \\
\text { And } \int_{0}^{\tilde{z}_{e}} k_{2}(z) d z-\int_{0}^{\tilde{z}_{e}} k_{1}(z) d z=\int_{\tilde{z}_{e}}^{1} k_{1}(z) d z-\int_{\tilde{z}_{e}}^{1} k_{2}(z) d z
\end{gathered}
$$

Redistribution in favor of those who do not emerge as entrepreneurs will adversely affect total output because everyone who is producing $X$ is facing a binding credit constraint. Asset reallocation away from them reduces production, but does not increase production by the beneficiary group. In Figure (2), (9) shifts to the left, increasing $P_{e}$. The critical factor is $\tilde{z}$. If asset redistributed from the rich to those around $\tilde{z}$, such that $\tilde{z}$ declines, then one would compare the change in extensive margin i.e. output increase due to entry of new entrepreneurs, with the offsetting effects of the intensive margin i.e. output reduction by the existing rich entrepreneurs. Once total output at any given price is affected, autarkic relative price of $X$ will also be different (inversely affected).

Consider a redistributive scheme that redistributes a part of the wealth of the relatively rich entrepreneurs to the non-entrepreneurs, the poorer group. Let $k_{1}(z)$ denote the initial distribution and let $\Delta_{1}$ be taxed from entrepreneurs ranked between $[\tilde{z}, 1]$, the richest group as $k_{1}^{\prime}>0$. The redistribution scheme is essentially given by $\int_{0}^{\tilde{z}_{1}} \Delta_{2}(z) d z=\Delta_{1}\left(1-\tilde{z}_{1}\right) \ldots$ (12)

with $\Delta_{2}(z)$ transferred to the relatively poor. Note that the new distribution $k_{2}(z)$ will have a new cutoff point $\tilde{z}_{2}$ and be related to the initial $\tilde{z}_{1}$ as follows.

$k_{2}\left(\tilde{z}_{2}\right)+\Delta_{2}\left(\tilde{z}_{2}\right)=k_{1}\left(\tilde{z}_{1}\right) \ldots(13)$

We assume uniform transfer $\Delta_{2}(z)=\Delta_{2}, \forall z$.

Then from (12) and (13) we get $k_{2}\left(\tilde{z}_{2}\right)=k_{1}\left(\tilde{z}_{1}\right)-\frac{\Delta_{1}\left(1-\tilde{z}_{1}\right)}{\tilde{z}_{1}} \ldots$ (14)

Thus $\tilde{z}_{2}=\tilde{z}_{2}\left(\tilde{z}_{1}, \Delta, \tilde{z}\right) \ldots(15)$

Since borrowing from the bank is proportional to the wealth holding and output of $X$ is nothing but the total amount of finance, one has to check whether such redistribution increases the amount of finance engaged in production. The tradeoff is between the additional capital that is engaged by fresh entrepreneurs and the extra capital lost in the process by a transfer to the continuing non-entrepreneurs. 
Output will decline iff,

$\int_{\tilde{z}_{1}}^{1} k_{1}(z) d z>\int_{\tilde{z}_{2}}^{1} k_{2}(z) d z \ldots$

Or, $\int_{\bar{z}}^{1} k_{1}(z) d z>\int_{\tilde{z}_{2}}^{\tilde{z}_{1}}\left(k_{1}(z)+\Delta_{2}\right) d z+\int_{\bar{z}}^{1}\left[k_{1}(z)-\Delta_{1}\right] d z$

Or, $\Delta_{1}\left(1-\tilde{z}_{1}\right)-\Delta_{2}\left(\tilde{z}_{1}-\tilde{z}_{2}\right)>\int_{\tilde{z}_{2}}^{\tilde{z}_{1}} k_{1}(z) d z$

Or, $\Delta_{1}\left(1-\tilde{z}_{1}\right)-\Delta_{1} \frac{\left(1-\tilde{z}_{1}\right)}{\tilde{z}_{1}}\left(\tilde{z}_{1}-\tilde{z}_{2}\right)>\int_{\tilde{z}_{2}}^{\tilde{z}_{1}} k_{1}(z) d z$

Or, $\Delta_{1}\left(1-\tilde{z}_{1}\right)-\Delta_{1}\left(1-\tilde{z}_{1}\right)\left(1-\frac{\tilde{z}_{2}}{\tilde{z}_{1}}\right)>\int_{\tilde{z}_{2}}^{\tilde{z}_{1}} k_{1}(z) d z$

Or, $\Delta_{1} \frac{\left(1-\tilde{z}_{1}\right)}{\tilde{z}_{1}} \tilde{z}_{2}>\int_{\tilde{z}_{2}}^{\tilde{z}_{1}} k_{1}(z) d z \ldots$

Note that $\Delta_{1} \frac{\left(1-\tilde{z}_{1}\right)}{\tilde{z}_{1}}=\Delta_{2}$ represents the magnitude of transfer and lower the $\Delta_{2}$, higher will be $\tilde{z}_{2}$. We can define $\tilde{z}^{*}$ such that $\Delta_{2} \tilde{Z}^{\star}{ }_{2}\left(\Delta_{2}\right)=\int_{\tilde{z}^{\star}{ }_{2}\left(\Delta_{2}\right)}^{\tilde{z}_{1}} k_{1}(z) d z \ldots(18$

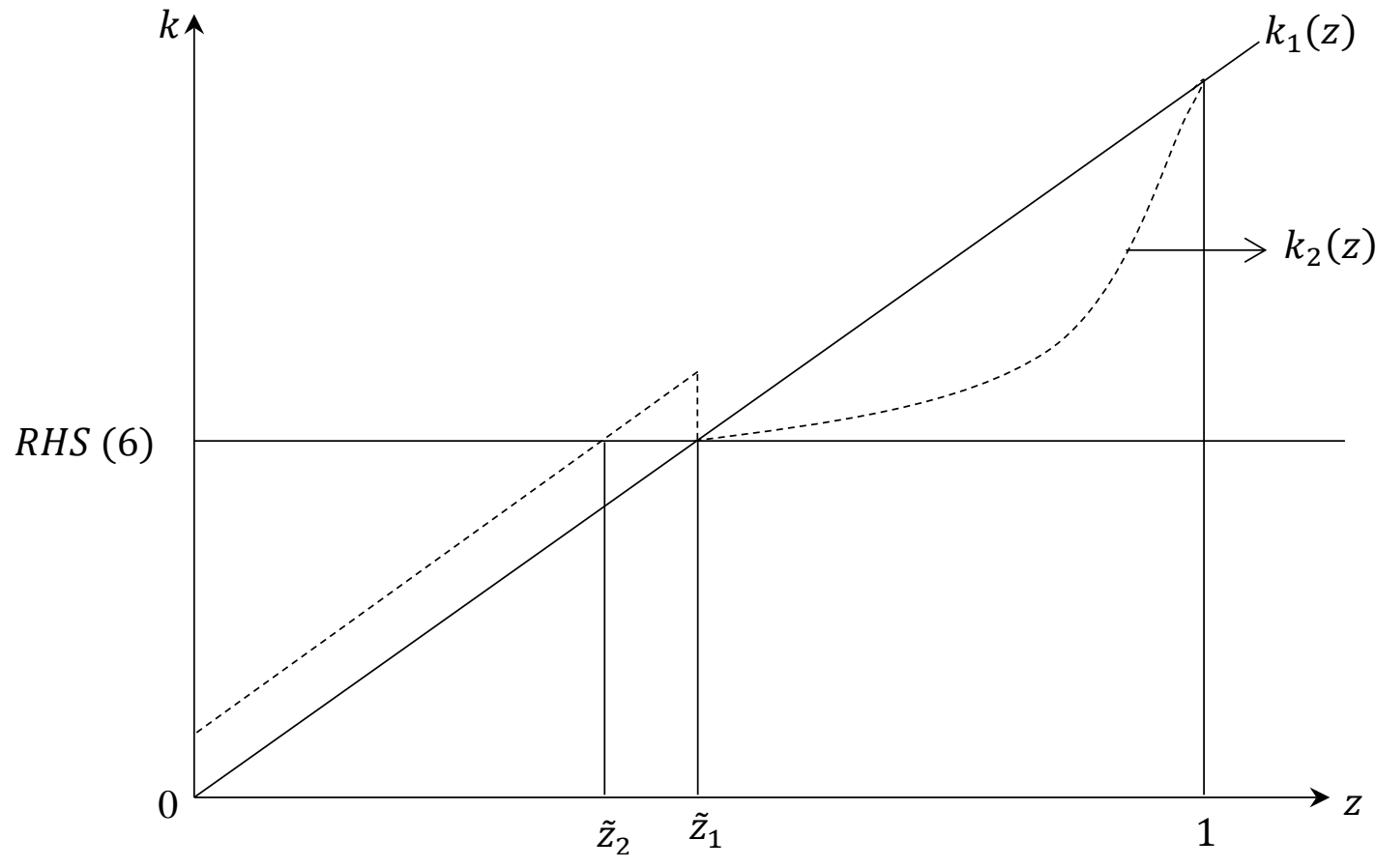

Fig 3(b)

\section{Proposition 2: $\forall \widetilde{z}_{2}>\widetilde{z}^{\star}{ }_{2}$, output of $X$ will decline with redistribution.}

Proof : As discussed above. QED.

Note that for (17) and (18) distribution of wealth itself is also important as with same $\Delta_{2}, \tilde{z}$ can be different depending on curvature of $k(z)$. But whatever it is, any arbitrary redistribution scheme will 
not guarantee efficiency. Any scheme that guarantee a $\tilde{z}$ below $\tilde{z}^{*}$ will increase production of $X$, otherwise not. In particular, redistribution tilted towards the bottom end, will be likely to be inefficient. Thus, unchanged or not substantially lower $\tilde{z}$ will do the trick. From now on we shall consider the case where egalitarian redistribution or a more equally distributed wealth actually reduces production of $X$ and increases its autarkic relative price. Thus, relatively equal distribution of wealth would mean import of the credit intensive good.

What we have clearly shown is that any egalitarian redistribution of $k$ must increase the number of entrepreneurs, for $X$ to increase in the sense that the loss due to a cut back in the intensive margin must be compensated by the extensive margin. However, the required fall in $\tilde{z}$ may have to be quite substantial. Targeting relatively well-off among the poor is desirable for expansion in the credit intensive factor.

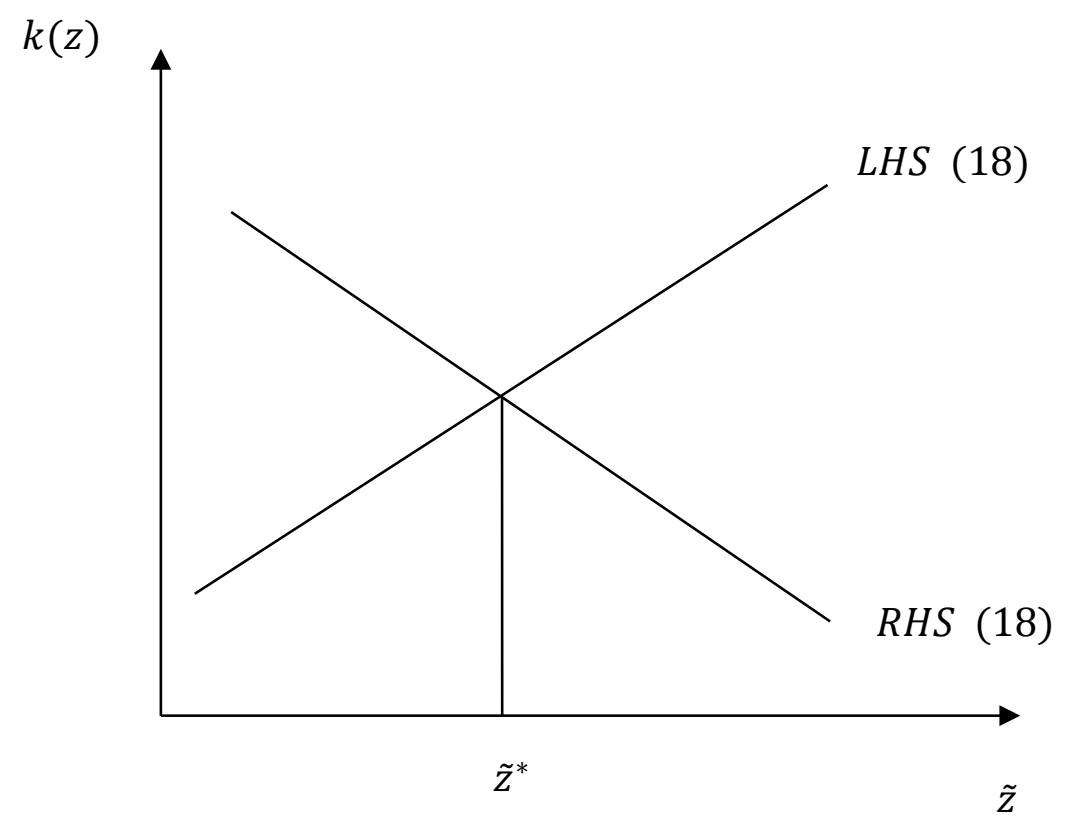

Fig 3(c)

In a paper, Stilianos and Konstantinos (2011) show, in context of regional inequality and growth, that equity and efficiency relationship is non-monotonic. For relatively high inequality, an equalizing redistribution is inefficient and for relatively low inequality, it is efficient. We provide a theoretical justification to this argument. If the poor non-entrepreneurs are really poor and far away from being 
entrepreneurs, any transfer of asset to them will not make them entrepreneurs and production of $X$ will suffer. But if the poor are concentrating around the cut-off point, it will be exactly the opposite.

Let us consider an increase in the relative price of $X$ as the country opens up for trade and exports $X$. This will affect $\tilde{z}_{e}$ and $\tilde{z}$ will fall up to $\tilde{z}_{T}$. We consider the income distribution between existing entrepreneurs and those who will not be entrepreneurs even after a decline in $\tilde{z}$. Since $r$ does not change and a higher $P$ increases income of the existing entrepreneurs, income distribution between $z \in\left[0, \tilde{z}_{T}\right]$ and $z \in\left[\tilde{z}_{e}, 1\right]$ with $\tilde{z}_{T}<\tilde{z}_{e}$ will go in favor of the richer segment. Hence trade will increase degree of inequality between entrepreneurs and non-entrepreneurs.

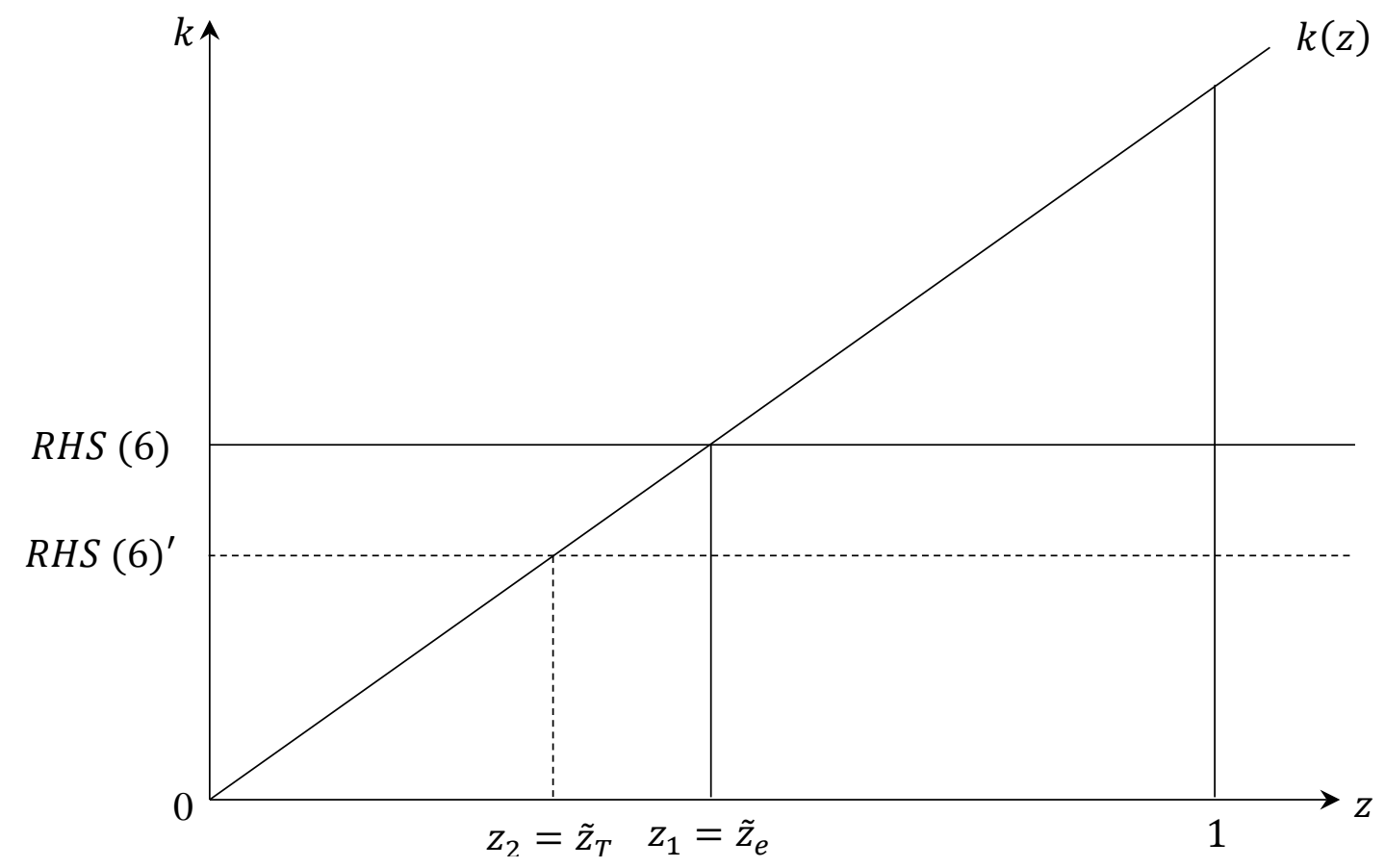

Fig 3(d)

Consider the distribution among the existing entrepreneurs. Let their income be denoted as $\Omega(z)$.

From (1) $\widehat{\Omega}(z)=\widehat{P} \ldots(19)$

Hence for any two existing entrepreneurs, rich or poor, income distribution does not change with trade. Now consider the new entrepreneurs and the existing ones and we need to compare.

$A_{1} \equiv \frac{\left.\left[\left(P_{e}-R\right) B\left(z_{1}\right)+\left(P_{e}-r\right)\right] k\left(z_{1}\right)\right]}{r+r k\left(z_{2}\right)}$ 
And

$A_{2} \equiv \frac{\left(P_{T}-R\right) B\left(z_{1}\right)+\left(P_{T}-r\right) k\left(z_{1}\right)}{\left(P_{T}-R\right) B\left(z_{2}\right)+\left(P_{T}-r\right) k\left(z_{2}\right)}$

Note that for the new entrepreneurs it is a finite jump. In particular let us look at $z_{2}=\tilde{z}_{T}$, the new cutoff point.

Using (5) $A_{2}$ can be reduced to,

$A_{2}=\frac{k\left(z_{1}\right)}{k\left(z_{2}\right)}$; where $B(z)=\alpha \cdot k(z) \ldots$ (20)

And $A_{1}=\frac{\left[\left(P_{e}-R\right) \alpha+\left(P_{e}-r\right)\right] k\left(z_{1}\right)}{r+r k\left(z_{2}\right)}$

$A_{2} \leq A_{1}$ iff $\frac{k\left(z_{1}\right)}{k\left(z_{2}\right)} \leq \frac{\left[\left(P_{e}-R\right) \alpha+\left(P_{e}-r\right)\right] k\left(z_{1}\right)}{r+r k\left(z_{2}\right)}$

Or, $r+r k\left(z_{2}\right) \leq\left[\left(P_{e}-R\right) \alpha+\left(P_{e}-r\right)\right] k\left(z_{2}\right)$

Or, $\frac{r}{k\left(z_{2}\right)}+r \leq\left(P_{e}-R\right) \alpha+\left(P_{e}-r\right) \ldots$

Note that for $z_{2}=\tilde{z}_{T}$ strict equality holds. Consider $\tilde{z}_{e}>z>\tilde{z}_{T}$ i.e., the set of fresh entrepreneurs. But we know that none of the fresh entrepreneurs chose to be entrepreneurs at $P_{e}$, hence (21) must hold in reverse and trade must increase the degree of inequality between old entrepreneurs and new entrepreneurs i.e. old ones gains more. But note that among the existing entrepreneurs the relative income remains unchanged from (20).

\section{Proposition 3: Export of the credit intensive good will lead to the following pattern of income distribution.}

a) Within the group of existing entrepreneurs, income distribution will not change between the rich and the poor.

b) Fresh entrepreneurs will be richer compared to the non-entrepreneurs but will be poorer compared to the existing entrepreneurs.

Proof: See the discussion above.

Usually trade is supposed to affect inequality by allowing those who can expand production by accessing more credit and not allowing those who cannot. Typically the rich benefit relative to the poor. But we show that this argument is invalid with competitive product market because everyone is 
utilizing credit up to their credit limit. A rise in relative price of $X$ does not increase production via the existing entrepreneurs but through fresh entry. However, all entrepreneurs gain because of an increase in the relative price relative to their opportunity cost of not being an entrepreneur. Whether trade necessarily leads to greater inequality depends on which group we are referring to. Among the existing entrepreneurs it remains unchanged. However, while fresh entrepreneurs gain relative to the nonentrepreneurs but they lose relative to the existing entrepreneurs.

With the assumption that competitive banking has to be the same for all the borrowers, each bank charges an intermediation cost $\mu>1$ over and abover.

Total supply of credit is given by $K^{s}=\int_{0}^{\tilde{z}} k(z) d z$ when $\tilde{z}$ is the cut-off point.

Similarly, demand for credit is given by $K^{d}=\int_{\tilde{z}}^{1}\left[\frac{q \theta}{\mu r-q \theta}\right] k(z) d z$.

Also $\tilde{z}$ is determined by (6).

The credit market clearing condition is as follows.

$\left(\frac{q \theta}{\mu r-q \theta}\right) \int_{\tilde{z}(r)}^{1} k(z) d z=\int_{0}^{\tilde{z}(r)} k(z) d z \ldots(22)$

From (6)

$k(\tilde{z})=\frac{1}{\left(\frac{P}{r}-\mu\right)\left(\frac{q \theta}{\mu r-q \theta}\right)+\frac{P}{r}-1} \ldots$

Hence, as $k^{\prime}>0, \tilde{z}^{\prime}(r)>0$

(22) and (23) imply that LHS in (22) is downward sloping and RHS in (22) is upward rising as shown in the following diagram.

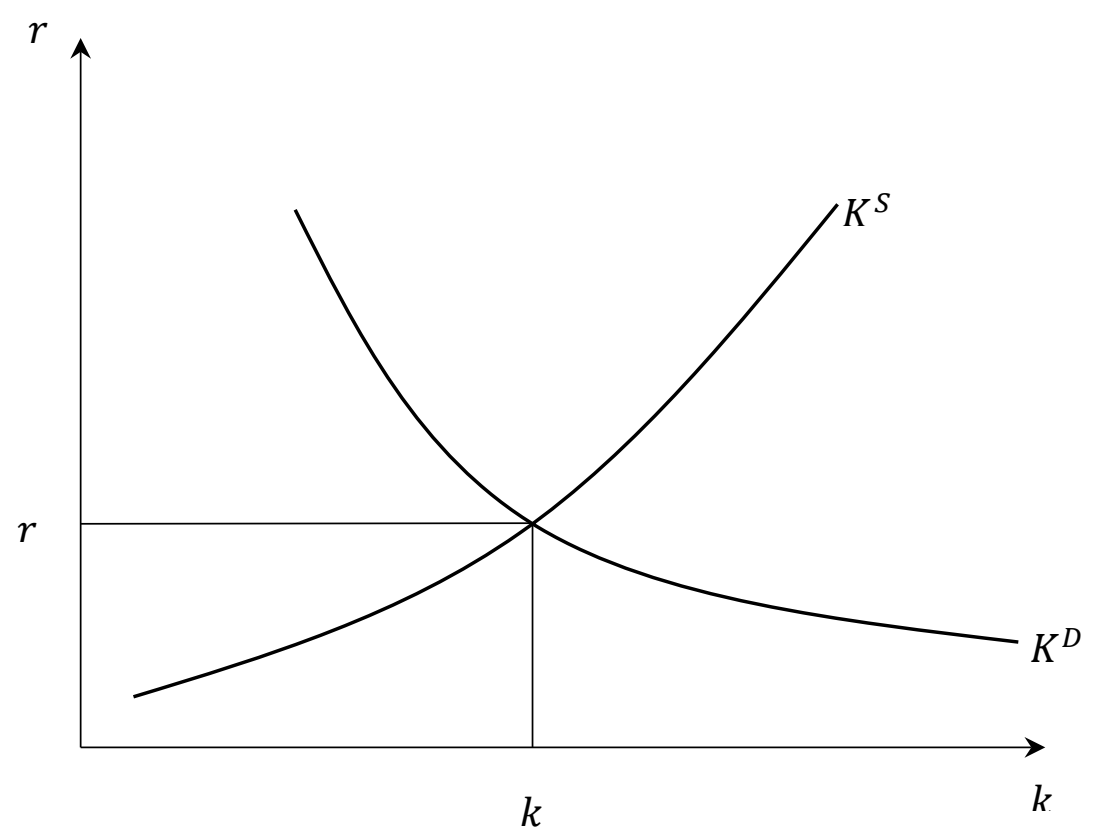

Figure (4) 
From (23) we know that as $P$ increases, $\tilde{z}$ must go down, shifting the demand up and supply down and thus leading to a rise in $r$. This defines the locus of $(P, r)$ as $K K$ in Figure (5). The commodity market equilibrium is also affected by changes in $r$. In Figure (2), higher $r$ will reduce supply of $X$ by raising $\tilde{z}$ and will increase $P$. This is defined as the locus $C C$ in Figure (5).

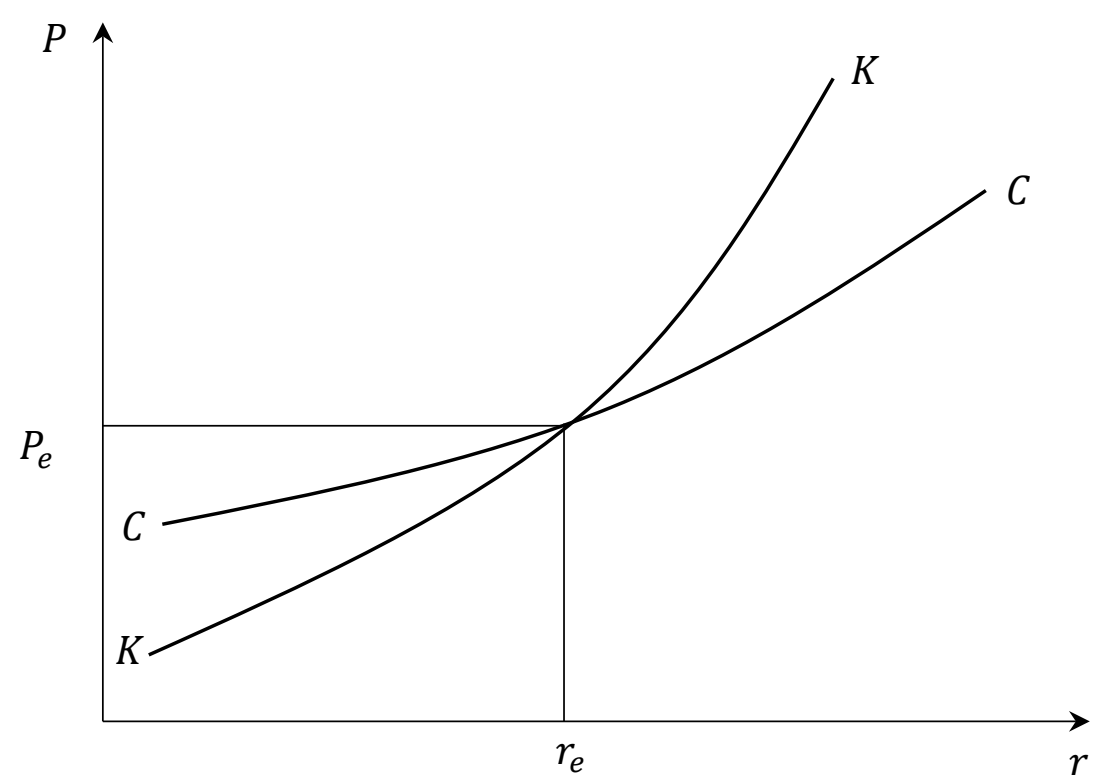

Figure (5)

$P$ adjusts along $C C$ and $r$ adjusts along $K K$. $\left(P_{e}, r_{e}\right)$ represent the general equilibrium solution of the system. They in turn determine $\tilde{z}, X$ and $Y$.

Let us repeat the impact of an egalitarian asset distribution, as suggested in the earlier section which does not alter $\tilde{z}$ to start with. As demonstrated earlier, at given $r, P$ will increase. Hence, $C C$ will shift upward in Figure (5). Also, given $P$, demand for credit shrinks and supply increases, hence $r$ must drop. So $K K$ will shift to the left. 


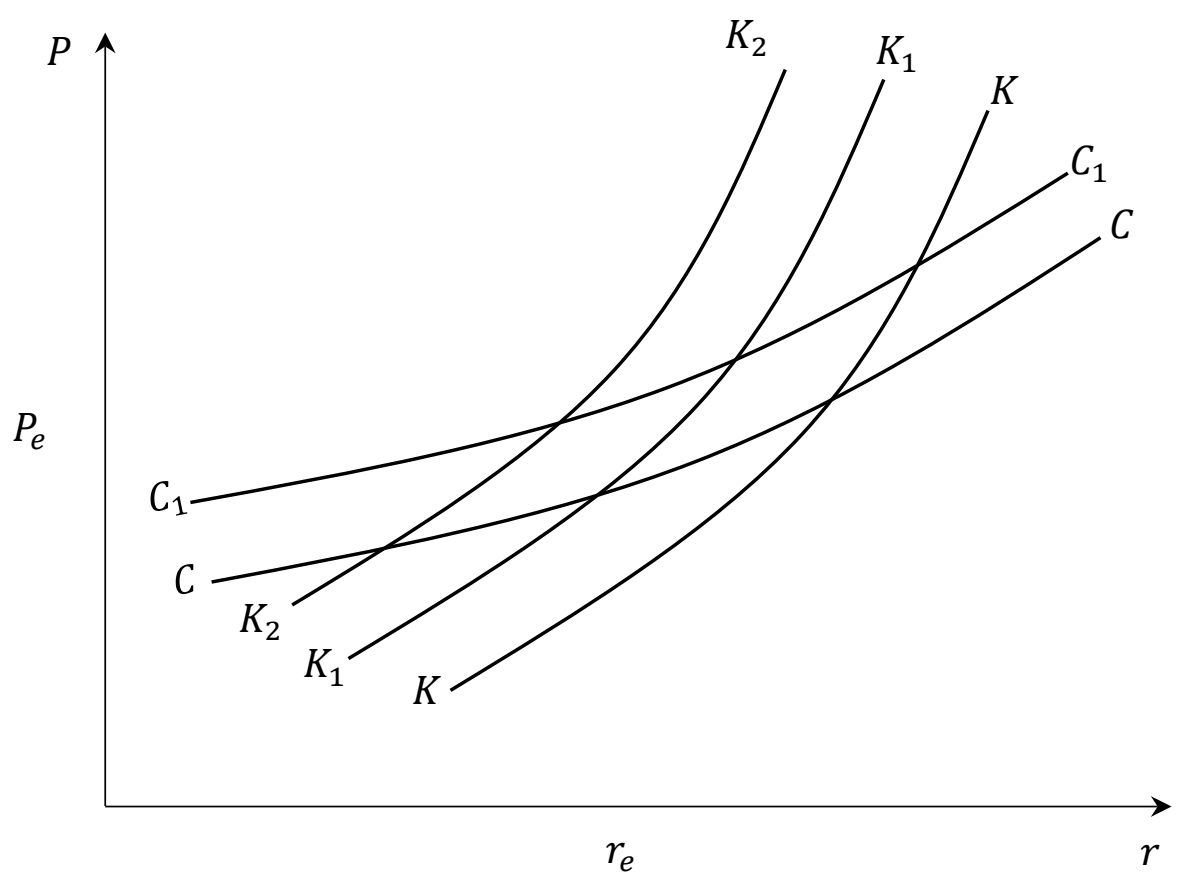

Figure (6)

With $K K$ shifting as $K_{1} K_{1}, P$ will rise and $r$ will fall. Thus, more egalitarian economy will import the credit intensive good and if opportunity arises capital and credit will flow out of the country. Thus more equal society will drive away capital and it eventually settles at a higher world rate of interest, the shift in $K K$ will be vertical at $r=r^{*}>r_{e}$, leading to even higher $P_{e}$.

In an egalitarian economy there are fewer entrepreneurs, there is less demand for capital and greater supply and hence $r$ tends to be lower. But this, despite there being less number of entrepreneurs, through increased credit limit to the existing entrepreneurs, has a positive effect on output. The tug of war between the intensive and extensive margins may reduce or increase $r$. This in part will depend on shift in the $K K$ curve. If it is pulled back a lot as in figure (6), $P$ and $r$ both may fall, thus the egalitarian economy may export credit intensive good. But for this to happen $r$ must fall and given a chance capital will flow out of this economy. Conditions for these results have been derived in the appendix in terms of a linearized version. 


\section{Concluding Remarks}

In this paper we show that in contrast to the common belief, more egalitarian asset distribution tends to reduce the output of the credit intensive sector if entrepreneurship is not encouraged. As compared to the inequality of asset distribution, product market imperfection leads to (has more impact on) the inefficiency. It is instructive to suggest why conventional wisdom which suggests that more even asset distribution is likely to be more efficient, is more likely to hold when product market is imperfect. Typically in an imperfectly competitive set up the firms will choose output where $P(Q)(1-1 / \mu)=$ $M C=R$ in our framework. $\mu$ is the elasticity of demand. In our paper elasticity is infinite and since $P>R$, the demand for loan is infinite as $Q=B+k$ at a given $k$. Even the richest exhausts her credit limit. If elasticity is finite and greater than 1 , as it has to be typically in an imperfect product market, above relationship will determine output. As $\mu$ drops, given $R, Q$ drops, demand for loan goes down, but the maximum credit limit is determined by the firm's asset position and institutional parameters, thus demand for loan can be less than the credit limit and the excess supply at the firm level will be increasing in the asset position of the firm. Such surplus credit could go to those who are credit rationed and the system will be more efficient. If we consider the level of asset for the rich, which is just sufficient to indicate a credit limit that is exactly equal to their loan demand and redistribute their extra asset to the poor, it cannot reduce output and an additional fresh entrepreneur will increase output. Thus, the fact that the superrich firms usually do not operate in competitive markets will drive the conventional result. On the other hand, if we redistribute assets from entrepreneurs that use up their credit limit to those who do not because they are substantially poor not to have much of a credit demand to engage in production, it will lead to inefficiency. Thus the importance of product market competition should not be neglected in such a discourse.

It is also shown that, inequality increases only across the groups and not within the groups of entrepreneurs. Further we show that a country characterized by an egalitarian distribution of assets would import credit intensive good from the rest of the world and export credit to the rest of the world. 


\section{References :}

Aghion, P. \& Banerjee, A. (2005). Volatility And Growth. Oxford University Press.

Antras, P. \& Caballero R. J. (2009). Trade and Capital Flows: A Financial Frictions Perspective. Journal of Political Economy, 17(4) 701-743.

Bandyopadhyay, Subhayu, Sugata Marjit, and Lei Yang. "International oligopoly, barriers to outsourcing and domestic employment." Canadian Journal of Economics 47.4 (2014): 13721386.

Banerjee, A. V. \& Newman, A. F. (1993). Occupational Choice and the Process ofDevelopment. Journal of Political Economy, 101(2), 274-298.

Bernanke, B. \& M. Gertler. (1989). Agency Costs, Net Worth and Business Fluctuations. The American Economic Review, 14-31.

Bencivenga, V. R. \& Smith, B. D. (1991). Financial Intermediation and Endogenous Growth.Review of Economics Studies, 58(2), 195-209.

Deardorff, A. V. (2000). Financial Crisis, Trade, and Fragmentation. Working Papers 458, Research Seminar in International Economics, University of Michigan.

Foellmi, R. \& Oechslin, M. (2010). Market Imperfections, Wealth Inequality, and the Distribution of Trade Gains. Journal of International Economics, 81(1), 15-25.

Galor, O. \& Zeira, J. (1993). Income Distribution and Macroeconomics. The Review of Economic Studies, 60(1), 35-52.

Galor, O. (2009). Inequality and Economic Development: The Modern Perspective. Edward Elgar.

Glenn Hubbard, R. (1991). Financial Markets and Financial Crises. University of Chicago Press.

Jones, R. W. \& Marjit, S. (2001). The Role of International Fragmentation in the Development Process. American Economic Review, 91(2), 363-366.

Lucas, R. E. (1990). Why Doesn't Capital Flow from Rich to Poor Countries? The American Economic Review, 80(2), 92-96.

Manova, K. (2013). Credit Constraints, Heterogeneous Firms and International Trade. The Review of Economic Studies, 80, 711-744.

Matsuyama, K. (2005). Credit Market Imperfections and Patterns of International Trade and Capital Flows. Journal of the European Economic Association, 3, 714-723.

Peters, K. \& Schnitzer, M. (2015) - Trade Liberalization and Credit Constraints -Why Opening up may fail to promote Convergence - Canadian Journal of Economics ( Forthcoming).

Piketty, T. (2013). Capital in the Twenty-First Century. The Belknap Press of Harvard University Press.

Rajan, R \& Zingales, L. (1998). Financial Dependence and Growth. American Economic Review, 88( 3), 559-586.

Sato, H. (2006). Entrepreneurship, Financial Market Imperfection and Trade. Mimeo, Hitotshubashi University. 
Schmidt-Eisenlohr, T. (2013). Towards a theory of trade finance. Journal of International Economics, 91 (1), $96-112$.

Stilinos, A \& Konstantinos, E. (2011). A Note on Inter-Regional Inequality and Economic Efficiency: Evidence from the US states. Reginal Science Policy and Practice, 1 (3), 37-44.

Wynne, J. (2005). Wealth as a Determinant of Comparative Advantage. American Economic Review, 95(1), 226-254. 


\section{Appendix}

The following are the basic equations for the product and credit markets respectively:

$$
\begin{aligned}
& P=\alpha+\beta r+\gamma z_{e g} \\
& r=a+b P-c z_{e g}
\end{aligned}
$$

where, $z_{e g}$ refers to an index that the asset distribution is egalitarian, with higher value denoting a more egalitarian distribution; the parameters $\alpha, \beta, \gamma, a, b$ and $c$ are positive real numbers.

$$
\begin{gathered}
\Rightarrow \begin{array}{c}
P-\beta r=\alpha+\gamma z_{e g} \\
-b P+r=a-c z_{e g}
\end{array} \\
\Rightarrow\left[\begin{array}{cc}
1 & -\beta \\
-b & 1
\end{array}\right]\left[\begin{array}{l}
P \\
r
\end{array}\right]=\left[\begin{array}{l}
\alpha+\gamma z_{e g} \\
a-c z_{e g}
\end{array}\right] \\
P=\frac{\left|\begin{array}{cc}
\alpha+\gamma z_{e g} & -\beta \\
a-c z_{e g} & 1
\end{array}\right|}{\left|\begin{array}{cc}
1 & -\beta \\
-b & 1
\end{array}\right|}=\frac{\alpha+\gamma z_{e g}+a \beta-\beta c z_{e g}}{(1-b \beta)}=\frac{\alpha+a \beta+(\gamma-\beta c) z_{e g}}{(1-b \beta)}
\end{gathered}
$$

And

$$
r=\frac{\left|\begin{array}{cc}
1 & \alpha+\gamma z_{e g} \\
-b & a-c z_{e g}
\end{array}\right|}{\left|\begin{array}{cc}
1 & -\beta \\
-b & 1
\end{array}\right|}=\frac{a-c z_{e g}+b \alpha+b \gamma z_{e g}}{(1-b \beta)}=\frac{a+b \alpha+(b \gamma-c) z_{e g}}{(1-b \beta)}
$$

Comparative Statics (the effect of a more egalitarian distribution on $P \& r$ ):

And

$$
\frac{\partial P}{\partial z_{e g}}=\frac{(\gamma-\beta c)}{(1-b \beta)}
$$

$$
\frac{\partial r}{\partial z_{e g}}=\frac{(b \gamma-c)}{(1-b \beta)}
$$

We have $1>b \beta$ (because $\frac{d P}{d r}$ along $K K$ is greater than $\frac{d P}{d r}$ along $C C$ (please see fig (5)) due to the stability argument. There does exist a chance that $c$ may fall in between $\beta$ and $\frac{1}{b}$, i.e. $\beta<\frac{\gamma}{c}<\frac{1}{b}$ or $b \gamma<c<\frac{\gamma}{\beta}$. Thus,

$$
\frac{\partial P}{\partial z_{e g}}=\frac{(\gamma-\beta c)}{(1-b \beta)}>0
$$


And

$$
\frac{\partial r}{\partial z_{e g}}=\frac{(b \gamma-c)}{(1-b \beta)}<0
$$

